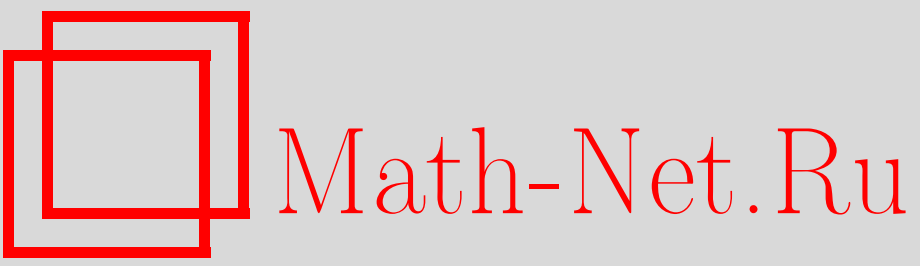

В. Л. Боднева, В. Г. Болтянский, И. М. Гельфанд, В. В. Дикусар, А. В. Дмитрук, А. Д. Иоффе, В. Л. Левин, Я. М. Каждан, Н. П. Осмоловский, В. М. Тихомиров, Г. М. Хенкин, Алексей Алексеевич Милютин (некролог), УМН, 2002, том 57, выпуск 3, 137-140

DOI: https://doi.org/10.4213/rm491

Использование Общероссийского математического портала Math-Net.Ru подразумевает, что вы прочитали и согласны с пользовательским соглашением

http://www. mathnet.ru/rus/agreement

Параметры загрузки:

IP : 52.6 .47 .48

26 апреля 2023 г., 12:56:43 


\section{АЛЕКСЕЙ АЛЕКСЕЕВИЧ МИЛЮТИН}

20 апреля 2001 г. на 76 -м году жизни скоропостижно скончался выдающийся российский математик Алексей Алексеевич Милютин. Обладая ярким талантом исследователя, А. А. Милютин всю свою жизнь посвятил беззаветному служению науке. Жажда познания нового, а также незаурядные воля и "искра божья" позволяли ему постоянно двигаться вперед, без устали осваивая новые и новые территории в той области математики, которая стала делом его жизни: в теории экстремума и - в наибольшей мере - в теории оптимального управления. Напряженная работа не прекращалась вплоть до самой последней его минуты: сердечный приступ случился во время выступления Алексея Алексеевича на семинаре по оптимальному управлению, постоянным руководителем которого он являлся около 40 лет.

А. А. Милютин родился 27 июля 1925 г. в Москве. Среднее образование, естественное развитие которого

было нарушено войной, Алексей Алексеевич завершил на специалшных курсах при Московском государственном университете. В 1943 г. он поступает на механико-математический факултет Московского университета. Успешно окончив его в 1948 г., А.А. Милютин получает рекомендацию в аспирантуру того же факултета.

Тогда же он начинает и преподавательскую работу - в 1951 г. он ведет упражнения по математическому анализу на первом курсе механико-математического факультета. Его студенты того года до сих пор рассказывают легенды о своем увлеченном наставнике, засиживавшимся порой со студентами до глубокой ночи, возвращающемся домой пешком по замершей Москве в сопровождении нескольких учеников (жил он в “доме на набережной”). Научная самостоятельность Милютина проявилась очень рано. В частности, он сам выбрал себе тему кандидатской диссертации. Она возникла из обсуждавшегося в университетских коридорах вопроса о том, являются ли линейно изоморфньми пространства непрерьвных функций на отрезке и на квадрате. А. А. Милютин дал положительньй ответ на этот вопрос в 1951 году. Он вошел в качестве одного из резултатов в его кандидатскую диссертацию.

Автор не подозревал, что тем самым он решил одну из известных проблем Банаха. Диссертация была защищена в том же году; оппонентами по ней были И. М. Гельфанд и Л. А. Люстерник. Удивительно, но и они не осознали, что диссертантом решена давно стоявшая знаменитая проблема. В результате решение осталось неопубликованным и еще 15 лет неизвестным математикам, пытавшимся решить эту проблему. Вопрос вновь был поднят на Международном математическом конгрессе в Москве в 1966 г. (во время доклада А. Пелчинского). К счастью, экземпляр диссертации сохранился в библиотеке факултета, и резултат был представлен на конгрессе, а позднее, благодаря инициативе и стараниям московских, харьковских и польских математи- 
ков, полностью опубликован (в сб. "Теория функций, функциональный анализ и их приложения", Харьков, 1966, № 2). Этот результат занимает весьма почётное место в общей теории банаховых пространств.

В диссертации А. А. Милютина было также доказано, что не существует линейного изоморфизма между пространствами непрерьвных функций на отрезке и на квадрате, которьй бы переводил $C^{1}$-функции двух переменных в $C^{1}$-функции одного переменного. Это доказательство основано на вычислении и сравнении числа точек $\varepsilon$-сетей компактов $C^{1}$-функций в равномерных нормах. Идеи Милютина были переоткрыты несколько лет спустя А. Г. Витушкиным и А. Н. Колмогоровым.

В 1950-х годах, занимаясь проблемой различения банаховых пространств $C^{1}$-функций одного и нескольких переменных, А. А. Милютин ввел в рассмотрение весьма мощный инвариант - "рост пространства", связанный со свойствами его вложения в универсалшное пространство. Эти идеи были позднее использованы Г. М. Хенкиным для различения банаховых пространств $C^{1}$-функций одного и нескольких комплексных переменных.

В 1954 г. вместе с другими молодыми выпускниками мехмата МГУ А. А. Милютин был привлечен к работе в вьчислительной группе Института физических проблем, созданной при академике Л. Д. Ландау и обслуживающей оборонную проблематику. В последующие годы, уже будучи сотрудником Института химической физики, А.А. Милютин продолжал много и успешно заниматься численным решением различных прикладных задач. Но все же основные его математические интересы лежали в области теории.

Принцип максимума Понтрягина, полученный в конце 50-х годов, определил судьбу многих математиков, в том числе А. А. Милютина и его коллеги и товарища А. Я. Дубовицкого. Продумывание вопросов, связанных с задачами оптимального управления и доказательством принципа максимума, привело А. Я. Дубовицкого и А. А. Милютина к новому осмыслению всей проблематики теории экстремальных задач. Эта концепция была изложена ими статье "Задачи на экстремум при наличии ограничений" (опубликованной в "Журнале вычислительной математики и математической физики", № 3 за 1965 г.), ставшей программной как для самих авторов, так и для многочисленных последователей, благодаря необычайной ясности, простоте и эффективности заложенных в ней идей (так назьваемая схема Дубовицкого-Милютина). В свое время появление этой концепции было большой сенсацией. Ей сразу воспользовались не только прямые специалисты, но и работавшие более широкой области: эти идеи, в частности, позволили распространить принцип максимума на новые классы задач, в том числе на задачи с фазовыми ограничениями.

Первьй итог проведенным исследованиям по принципу максимума был подведен А. А. Милютиным в его докторской диссертации, защищенной в 1966 г. в Институте прикладной математики АН СССР. Помимо общих резултатов в диссертации содержался первый пример так называемого четтеринга - экстремали, у которой при "посадке" на границу фазового ограничения наблюдается счетное число контактов с границей.

Далее, в конце $60-x$ и в $70-е$ годы в серии работ А.Я. Дубовицкий и А.А. Милютин строят теорию принципа максимума для задач с регулярными и нерегулярными смешанными ограничениями. Их замечательным достижением явился "локальный принцип максимума" для нерегулярных смешанных ограничений (т.е. совместных ограничений общего вида на фазовые переменные и управления), опубликованньй в монографии "Необходимые условия экстремума в общей задаче оптимального управления", М., Наука, 1971.

Дальнейшие усилия авторов были направлены на получение "интегрального" принципа максимума для задач с нерегулярными смешанными ограничениями. А. А. Милютину удалось найти новую форму (первоначалшная содержалась в его совместных работах с А. Я. Дубовицким) представления условий принципа максимума, отражающую множественность и иерархию этих условий в общей задаче, а также новые пути их получения. Изложение этого материала составило содержание книги А. А. Милютина по теории принципа максимума, вышедшей в Физматлите в 2001 году.

В конце $60-$ х годов А.А. Милютин начинает работать на кафедре Общих проблем управления механико-математического факультета МГУ. Он был одним из первых лекторов курса "Оп- 
тимальное управление" на факултете, что оказало большое влияние на многие последующие книги по этому предмету. На семинаре, проводившемся совместно с Е. С. Левитиным, Алексей Алексеевич начинает интенсивные исследования по теории условий высших порядков. Он ставит вопрос о получении в оптимальном управлении необходимых условий второго порядка для задач с ограничениями типа неравенств, связанных с достаточными условиями столь же тесно, как это имеет место в задачах анализа и вариационного исчисления. Исследования привели к созданию абстрактной теории условий высших порядков в задачах с ограничениями, опубликованной в статье Е. С. Левитина, А. А. Милютина и Н. П. Осмоловского в УМН, 1978, т. 33, № 6. Абстрактная теория дала совершенно новые подходы к получению условий высших порядков в оптимальном управлении и позволила ученикам А. А. Милютина построить полную теорию квадратичных условий как в случае неособых (Н.П. Осмоловский), так и в случае особых (А. В. Дмитрук) оптимальных режимов.

В конце 70-х годов А.А. Милютиным была доказана замечательная "теорема о конечной коразмерности" (сб. "Методы теории экстремальных задач в экономике”, М., Наука, 1981), вскрьвшая истинный смысл целой серии результатов других авторов по необходимым условиям высших порядков для особых режимов в оптималшном управлении.

В эти же годы А. А. Милютин нашел удачное обобщение известной теоремы Люстерника о касательном подпространстве на произвольные метрические пространства, представив ее как теорему о накрывании (УМН, 1980, т. 35, № 6). Эта трактовка приобрела широкую популярность среди специалистов по нелинейному анализу.

Примерно с середины 80-х А.А. Милютина все болше занимают проблемы, связанные не с получением новых условий экстремума, а с тем, как сделать эти условия рабочим аппаратом для исследования задач оптимального управления. Так появляются теоремы об отсутствии скачков и сингулярных составляющих у мер - множителей Лагранжа при фазовых ограничениях в условиях принципа максимума, вошедшие в монографию "Необходимое условие в оптимальном управлении", М., Наука, 1990.

С помощью принципа максимума исследуются особенности экстремалей типа четтеринга, возникающие при посадке на границу фазового ограничения и при переходе с неособого режима на особый. Полученные результаты изложены в монографиях В. В. Дикусара и А. А. Милютина "Качественные и численные методы в принципе максимума", М., Наука, 1989, и А. А. Милютина, А.Е. Илютовича, Н.П. Осмоловского и С. В. Чуканова "Оптимальное управление в линейных системах", М., Наука, 1993. При помощи квадратичных условий А. А. Милютин исследует свойство жесткости траекторий управляемых систем (Труды ММО, 1999, т. 60) и особые геодезические относително субримановых метрик.

В теории квадратичных условий возник вопрос о возможности приближения произвольного векторного поля в конечномерном пространстве градиентными полями. А. А. Милютин находит формулу двойственности, которая связывает нормированную циркуляцию векторного поля с расстоянием от этого поля до множества градиентных векторных полей (Russian J. Math. Phys., 1995, v. 3, № 1).

Исследования по теории экстремума привели А.А. Милютина и его коллег к новым идеям и глубоким нетривиальным результатам в таких областях как математическая теория вибраций (Russian J. Math. Phys., 1997, v. 5, № 2, совм. с В. Л. Бодневой), асимптотический метод Крылова-Боголюбова (УМН, 1987, т. 42, № 3, совм. с В. Л. Бодневой), двойственность в задаче Монжа-Канторовича о перемещении масс (УМН, 1979, т. 34, № 3, совм. с В. Л. Левиньп), принцип максимума для дифференциальных включений, диффференциальные уравнения с разрывной правой частью, интегральные квадратичные формы на бесконечном интервале. А. А. Милютину удалось переосмыслить идеи вариационного исчисления и распространить их на новьй тип минимума - так назьваемый понтрягинский минимум, - характерньй для задач оптимального управления. Построенная теория изложена в монографии А. А. Милютина и Н.П. Осмоловского "Вариационное исчисление и оптимальное управление" (Providence, RI: Amer. Math. Soc., 1998).

В исследованиях А. А. Милютина, во многом опередивших свое время, содержатся и плодотворные идеи, и глубокие теоремы, и большое число ярких примеров, являющихся свидетельством его выдающегося дара и творческой силы. 
Алексей Алексеевич был безусловным лидером в области оптимального управления, оказавшим стимулирующее влияние на многих исследователей в разных областях математики. Он был незаурядной личностью и прожил свою жизнь честно и бескомпромиссно. Его внезапная смерть явилась полной неожиданностью для всех, кто его знал - учеников, коллег и близких. Светлая память об Алексее Алексеевиче навсегда сохранится в наших сердцах.

В. Л. Боднева, В. Г. Болтянский, И. М. Гельфанд, В. В. Дикусар, А.В. Дмитрук, А. Д. Иоффе, В. Л. Левин, Я. М. Каждан, Н. П. Осмоловский, В. М. Тихомиров, Г. М. Хенкин 